\title{
Ulnar artery pseudoaneurysm in a patient with factor IX deficiency (hemophilia B)
}

\author{
Mathew A Plant, Christopher G Scilley MD FRCSC
}

\begin{abstract}
MA Plant, CG Scilley. Ulnar artery pseudoaneurysm in a patient with factor IX deficiency (hemophilia B). Can J Plast Surg 2007;15(4):223-225.

The hypothenar hammer syndrome describes a constellation of symptoms resulting from repetitive trauma to the hypothenar eminence, often due to the use of the hand as a hammer. Sequelae of this syndrome include both true and false aneurysms, as well as thrombosis of the ulnar artery due to its vulnerability to blunt trauma as it exits Guyon's canal. Although this is a relatively well-documented phenomenon, an extensive review of the literature revealed that no cases have been described involving a patient with hemophilia. The present case describes a 46-year-old farmer with factor IX deficiency (hemophilia B) presenting with a $5 \mathrm{~cm} \times 7 \mathrm{~cm}$ pseudoaneurysm of the ulnar artery of the right hand.
\end{abstract}

\section{Pseudoanévrisme de l'artère cubitale chez un patient atteint d'un déficit en facteur IX, ou hémophilie $\mathrm{B}$}

\begin{abstract}
Le syndrome hypothénarien du marteau regroupe une constellation de symptômes qui résultent d'un traumatisme répété à l'éminence hypothénarienne, souvent attribuable à l'utilisation de la main comme marteau. Les séquelles de ce syndrome incluent des anévrismes, vrais et faux, de même qu'une thrombose de l'artère cubitale due à sa vulnérabilité aux traumatismes fermés au niveau de sa sortie du canal de Guyon. Bien qu'il s'agisse d'un phénomène relativement bien documenté, une analyse approfondie de la littérature a révélé qu'aucun cas n’avait encore été décrit chez la population hémophile. Le présent cas est celui d'un fermier de 46 ans atteint d'un déficit en facteur IX (hémophilie B) présentant un pseudoanévrisme de $5 \mathrm{~cm} \times 7 \mathrm{~cm}$ de l'artère cubitale de la main droite.
\end{abstract}

Key Words: Hemophilia B; Hand; Hypothenar hammer; Pseudoaneurysm; Ulnar artery

\begin{abstract}
$\mathrm{O}$ cclusive disease of the upper limb secondary to repeated trauma is a well-documented phenomenon, especially among individuals who subject their hands to repeated palmar stress (1-8). Specific mechanisms of palmar stress include the repeated use of high-speed vibratory tools (1), excessive weight bearing on a cane (1) and, most commonly, using the hand as a hammer. The sequelae of using the hypothenar eminence as a hammer have been described as early as 1934 (8) and include thrombosis (with or without distal embolic events), or aneurysm and pseudoaneurysm with varying degrees of ischemic disease distal to the injury. Although many cases have been described since then, there has been no description in the literature of the hypothenar hammer syndrome occurring in an individual with factor IX deficiency (hemophilia B), as is the case with our patient.
\end{abstract}

\section{CASE PRESENTATION}

A 46-year-old farmer with a known factor IX deficiency and positive hepatitis $\mathrm{C}$ virus serology presented following a fall on his extended hand, resulting in a hyperextension injury. He complained of new-onset changes in the sensory distribution of the ulnar and median nerves and a $2 \mathrm{~cm}$ to $3 \mathrm{~cm}$ pulsatile mass on the hypothenar eminence of the right hand. This injury occurred in addition to a long history of repetitive use of the hand as a hammer and a 10-year history of a pulsatile mass on the right palm. The mass was initially assumed to be a hematoma by the family physician and was aspirated. The patient was started on two days of recombinant factor IX treatment; however, his symptoms only marginally improved and the patient was referred to the plastic surgery department at the Shulich School of Medicine, London, Ontario, for further evaluation. An ultrasound at the time of initial assessment diagnosed a pseudoaneurysm measuring $1.9 \mathrm{~cm} \times 2 \mathrm{~cm} \times 1.4 \mathrm{~cm}$ arising from the ulnar artery distal to the carpometacarpal joint; however, the patient elected not to have it treated at that time because the harvest season was underway.

The patient returned one year later with a one-month history of a doubling in size of the palmar mass (Figure 1). An angiogram confirmed the presence of the pseudoaneurysm (Figure 2), a $60 \%$ to $70 \%$ narrowing of the ulnar artery and a narrowed, but patent, superficial palmar arch and good collateral flow from the deep arch, which was determined to be the current primary source of blood supply for the little finger and the ulnar aspect of the ring finger.

The patient was given a preoperative infusion of factor IX, and the pseudoaneurysm was observed intraoperatively to have increased in size to approximately $5 \mathrm{~cm} \times 7 \mathrm{~cm}$ (Figure 3 ). This was resected along with a $1.5 \mathrm{~cm}$ segment of the ulnar artery, which was then closed with direct microvascular reanastomosis (Figure 4). At one-month postoperative follow-up, the patient demonstrated improved hand function and his Allen's test indicated patency of the ulnar artery. At threemonth follow-up, the wound had completely healed with no evidence of recurrence (Figure 5). 


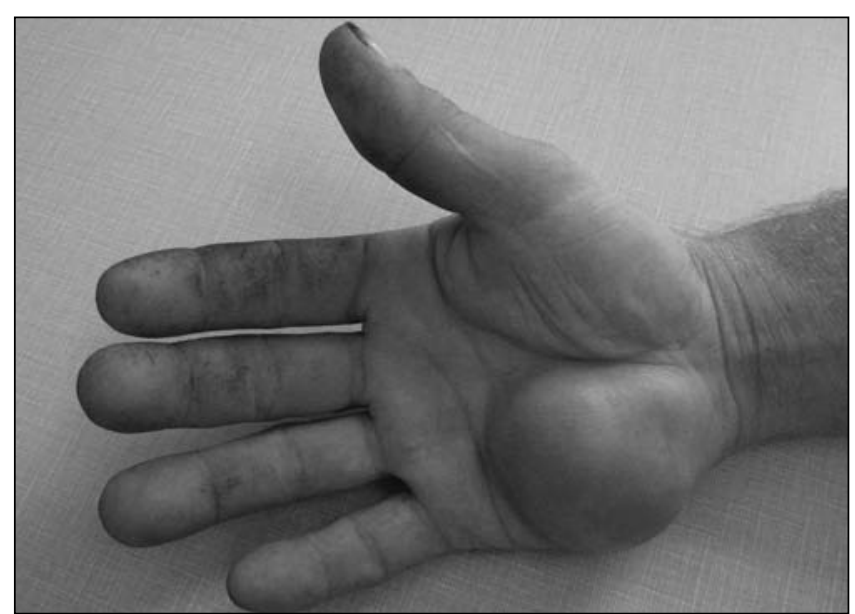

Figure 1) Palmar mass before excision

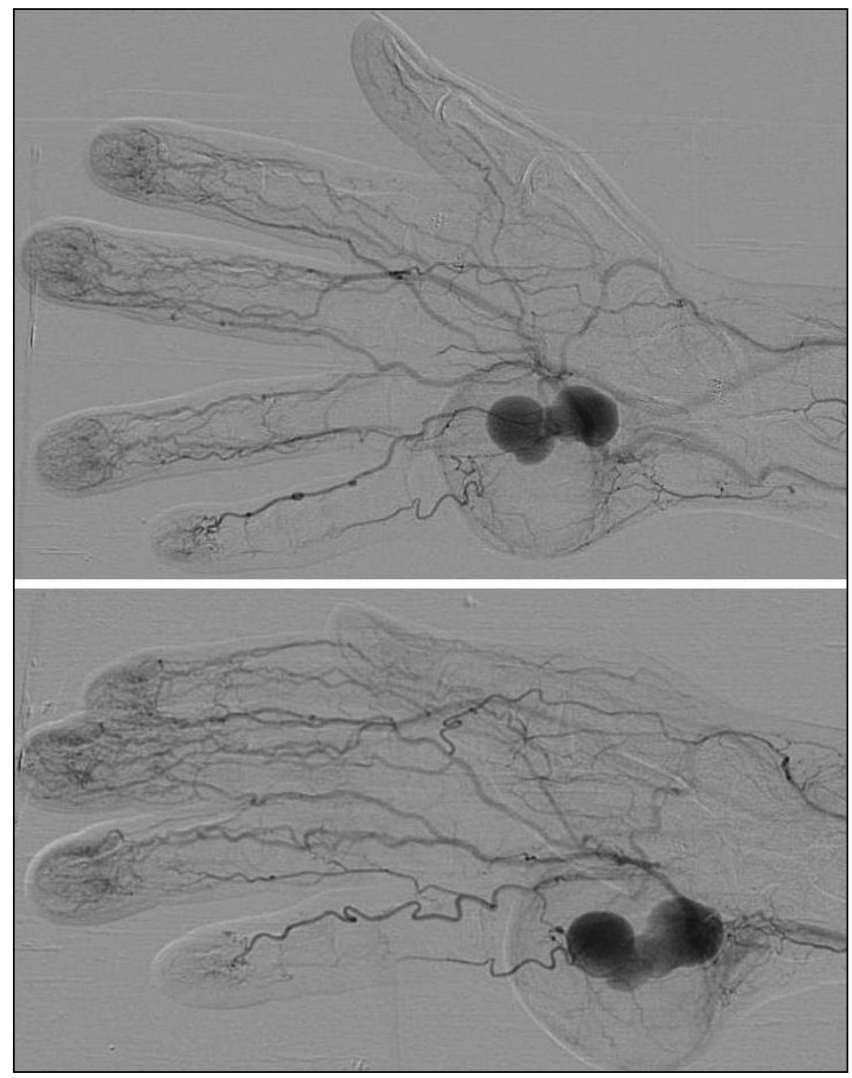

Figure 2) Preoperative angiogram

\section{DISCUSSION}

The hypothenar hammer syndrome describes a constellation of symptoms resulting from repetitive trauma to the hypothenar eminence, often due to use of the hand as a hammer.

The clinical findings associated with the hypothenar hammer syndrome range from simple localized tenderness over the hypothenar eminence to neurological symptoms secondary to compression of the ulnar nerve or branches thereof, or symptoms associated with arterial insufficiency and ischemia secondary to thrombosis or aneurysmal dilation of the ulnar artery (2). Specific signs may include a pulsatile or pulseless mass, positive Allen's test, decreased refill, changes to the nail bed, and ulceration and or gangrene of the digits distal to the blockage (4);

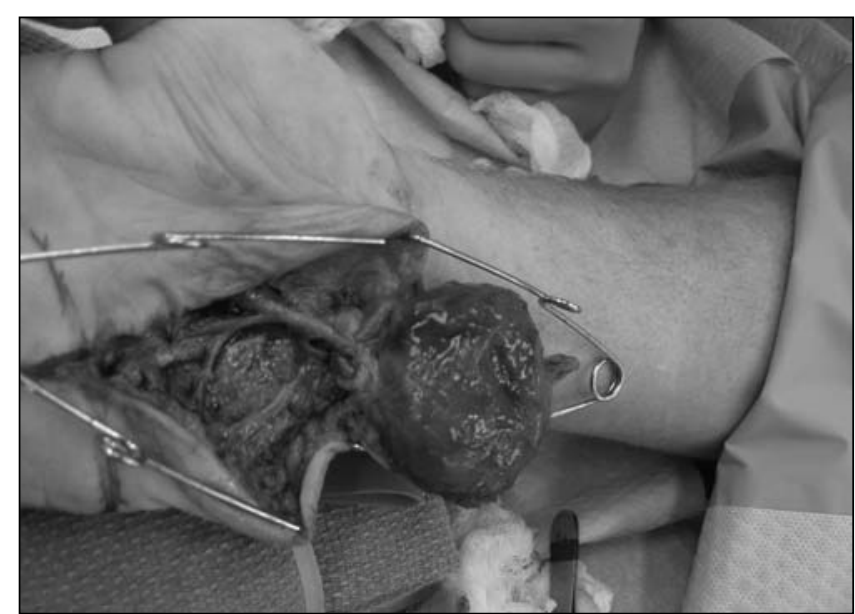

Figure 3) Intraoperative photo of pseudoaneurysm before excision

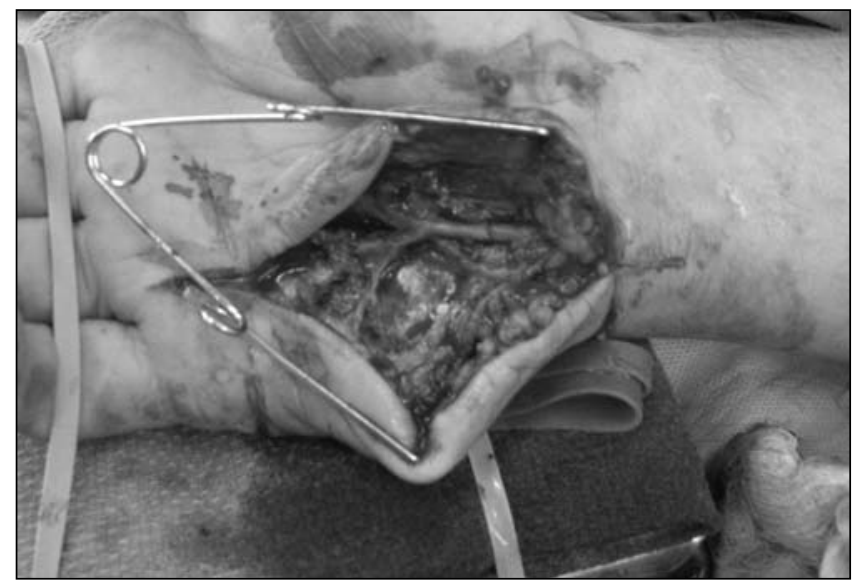

Figure 4) Intraoperative photo of reanastomosed ulnar artery

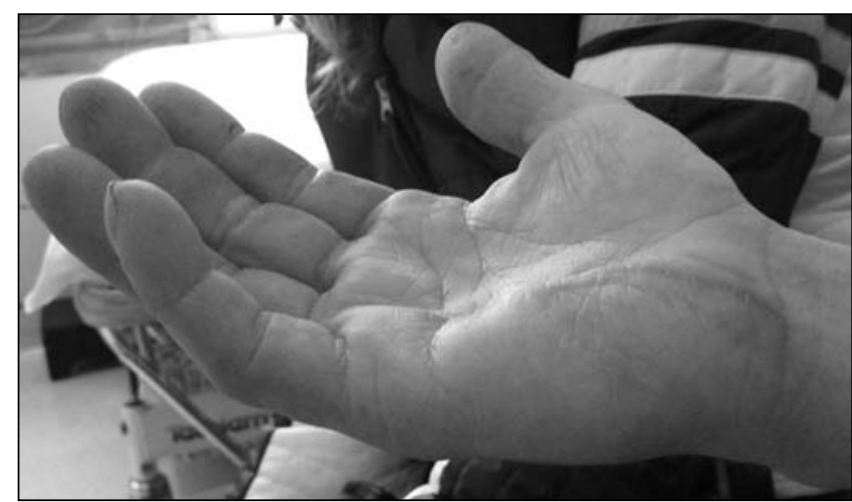

Figure 5) Three-month postoperative follow-up

however, imaging is generally necessary to make a firm diagnosis. Imaging modalities to determine the presence of an ulnar artery aneurysm can include Doppler ultrasound and colour duplex scanning; however, the gold standard is arteriography because it will not only identify the primary lesion, but it can also assess the extent of the local damage, identify distal emboli and differentiate the aneurysm from other masses. Furthermore, arteriography allows evaluation of collateral flow, identification of reconstructible vessels and facilitation of preoperative planning (4). 
The hypothenar hammer syndrome is seen most commonly in middle-aged male labourers with a history of using the hand as a hammer and of using tobacco products. Furthermore, pre-existing damage to the ulnar artery as a result of the tobacco use (2), atherosclerosis (4), fibromuscular dysplasia (6) or other collagen vascular diseases (ie, Marfan syndrome, Ehlers-Danos syndrome) (5) has been a common finding in patients suffering from the hypothenar hammer syndrome, and is thought to render the ulnar artery more susceptible to trauma. The ulnar artery is particularly vulnerable to traumatic damage where it exits Guyon's canal and passes over the hook of the hamate, because the local anatomy essentially results in the ulnar artery being "trapped between a 'hammer' (ie, external trauma) and an 'anvil' (ie, the hamate bone)," with only a thin layer of tissue superficially to protect it (2).

The postulated mechanism of formation for pseudoaneurysms involves a break in the endothelium (generally secondary to blunt or penetrating trauma) with subsequent extravascular hematoma formation, reorganization of the clot and recanalization of the vasculature through a newly formed false lumen (9). Because of the clotting deficiencies in hemophiliacs, there is increased extravasation of blood following trauma, allowing for the formation of a larger hematoma than would be expected in an individual with normal clotting abilities.

\section{REFERENCES}

1. Conn J, Bergan JJ, Bell JL. Hypothenar hammer syndrome: Posttraumatic digital ischemia. Surgery 1970;68:1122-8.

2. DeMonaco D, Fritsche E, Rigoni G, Schlunke S, Von Wartburg U. Hypothenar hammer syndrome. Retrospective study of nine cases. J Hand Surg [Br] 1999;24:731-4.

3. Dethmers RS, Houpt. Surgical management of hypothenar and thenar hammer syndromes: A retrospective study of 31 instances in 28 patients. J Hand Surg [Br] 2005;30:419-23.

4. Erdoes LS, Brown WC. Ruptured ulnar artery pseudoaneurysm. Ann Vasc Surg 1995;9:394-6.

5. Nguyen DQ, Murison M. Ulnar artery aneurysm in a patient with Marfan's syndrome. Plast Reconstr Aesthet Surg 2006;59:1131-2.

6. Taylor LM Jr. Hypothenar hammer syndrome. J Vasc Surg 2003;37:697.

7. Unlü Y, Ceviz M, Polat P. False aneurysm in the palmar segment of the ulnar artery: Report of a case. Surg Today 2003;33:148-50.

8. Von Rosen S. Ein Fall von Thrombose in der arteria ulnaris nach einwirkung von stumpfer gewalt. Acta Chirurgica Scandinavica 1934;73:500-6.

9. Wang AA, Strauch RJ, Moore JA. Pseudoaneurysm of the ulnar artery occurring after fracture of the distal radius and ulna: a case report. J Hand Surg [Am] 1998;23:933-7. 